\title{
spoVH and spoVJ - New Sporulation Loci in Bacillus subtilis 168
}

\author{
By SUSAN H. A. HILL \\ Microbiology Unit, Department of Biochemistry, University of Oxford, Oxford OXI 3QU, U.K.
}

(Received 25 May 1982; revised 23 June 1982)

\begin{abstract}
Three sporulation mutants have been isolated which produce spores with an atypical resistance phenotype, i.e. they are sensitive to organic solvents and heat but resistant to lysozyme. All three mutants produced serine protease, alkaline phosphatase and glucose dehydrogenase which are biochemical marker events for stages I, II and III. Two of the three mutants produced dipicolinic acid, a late marker, but the third was defective in its production. Heat-resistance was not restored to any of the mutants by the provision of exogenous dipicolinate. Gel electrophoresis showed that the mutant spores had similar patterns of spore coat proteins to the wild-type and electron microscopy revealed no significant structural differences. The three mutations responsible for the phenotypes of the mutant spores lie in the phe-argA region of the Bacillus subtilis chromosome. Recombination index values indicate that the mutations are in three separate genes. They define at least two new sporulation loci, designated spoVH and spoVJ.
\end{abstract}

\section{INTRODUCTION}

Late events in sporulation of Bacillus subtilis include the deposition of spore coat proteins, the development of germination properties and the successive acquisition of resistance to organic solvents, heat and lysozyme (Dion \& Mandelstam, 1980; Jenkinson et al., 1980). Evidence presented by Dion \& Mandelstam (1980) and Jenkinson et al. (1980) suggests that the late events in sporulation, occurring at stages V and VI, involve the assembly of proteins, most of which are synthesized before or during stage IV. Only one of the late events, the acquisition of complete lysozyme resistance, requires the presence of a spore coat protein (mol. wt 36000) which is not synthesized until stage VI (Jenkinson et al., 1981 ; Jenkinson, 1981). It is therefore apparent that the 'dependent sequence of events' thought to reflect the order of expression of sporulation genes in the earlier stages of the process (Mandelstam, 1969, 1976; Piggot \& Coote, 1976) does not hold during the later stages. Instead, the successive acquisition of late properties depends on the order of assembly of pre-formed proteins (Dion \& Mandelstam, 1980; Jenkinson et al., 1980, 1981). It should, therefore, be possible to isolate mutants in which a 'late' property is normal while an 'earlier' one is defective. We have now been able to show that mutants with this previously unexpected phenotype do exist and in this paper the isolation and characterization of three organic solvent-sensitive, heat-sensitive but lysozyme-resistant mutants are described. The mutations carried by these three mutants identify two new sporulation loci.

\section{METHODS}

Chemicals. Unless otherwise stated chemicals were obtained from Sigma.

Organisms. Bacillus subtilis Marburg 168 trpC2 which requires either indole or tryptophan and which sporulates normally is referred to as the wild-type. Details of sporulation defective ( $\mathrm{Spo}^{-}$) mutants derived from 168 and Spo $^{+}$ auxotrophic strains used for genetic analysis are shown in Table 1. \footnotetext{
index.

Abbreviations: DPA, 2,6-dipicolinic acid; NTG, $N$-methyl- $N^{\prime}$-nitro- $N$-nitrosoguanidine; RI, recombination
} 
Table 1. Strains of Bacillus subtilis used

Strain

Genotype

Phenotype

Source $\dagger$

$168 \quad \operatorname{trpC2}$

516 trpC2 spoVH516

517 trpC2 spoVJ517

$518 \quad$ trpC2 spoVH 518

MB21 metC2 leuA8

Cu448 pheA2 ilvBA1 argA2 trpC2*

517.21 metC3 leu ${ }^{+}$spoVJ517

516.21 metC3 leu $^{+}$spoVH516

518.21 metC3 leu $^{+}$spoVH518

516.448 ilvB spoVH516 phe trpC2 argA

517.448 ( $\mathrm{Spo}^{-}$, heat-sensitive, lysozyme-resistant PBS1 (517) $\times \mathrm{Cu}_{448}$; $\mathrm{ArgA}^{-}$ $518.448 \mathrm{ilvB}$ spoVH518 phe $\operatorname{trpC} 2 \arg \mathrm{A}^{+} \mathrm{Spo}^{-}$, heat-sensitive, lysozyme-resistant PBS1 (518) $\times \mathrm{Cu} 448 ; \mathrm{ArgA}^{-}$

* $i l v B \Delta I$ is a deletion which covers all known sites in ilvB but does not extend into $i l v C$.

${ }^{+}$'PBS1 (A) $\times$B; Aux $^{-}$' means that phage PBS1 grown on strain A was used to transduce strain B; Aux ${ }^{+}$ transductants were selected and the spo marker was acquired by cotransduction.

Induction of sporulation. Bacteria were grown in a hydrolysed casein medium at $37^{\circ} \mathrm{C}$ with shaking until the culture contained $0.25 \mathrm{mg}$ dry wt bacteria $\mathrm{ml}^{-1}$, and were then resuspended to the same density in warm $\left(37^{\circ} \mathrm{C}\right)$ resuspension medium (Sterlini \& Mandelstam, 1969). Incubation at $37^{\circ} \mathrm{C}$ with shaking was continued. The time of resuspension and subsequent hourly intervals are referred to as $t_{0}, t_{1}, t_{2}$, etc. About $80-90 \%$ of wild-type cells contained phase bright spores by $t_{8}$. The stages of sporulation are those described by Ryter (1965). Culture density was determined by absorbance measurements at $600 \mathrm{~nm}$ in a Unicam SP600 spectrophotometer and these were converted to units of $\mathrm{mg}$ dry wt bacteria $\mathrm{ml}^{-1}$ with a calibration curve.

Auxotrophic requirements of strains were satisfied by the inclusion of tryptophan at $20 \mu \mathrm{g} \mathrm{ml}^{-1}$ and all other appropriate amino acids at $200 \mu \mathrm{g} \mathrm{ml}^{-1}$ in minimal media.

Determination of spore incidence. Spores were counted by phase contrast microscopy and expressed as a percentage of the total number of cells. The term phase bright describes all gradations from dull white to bright spores; earlier visible spores are termed phase grey.

Isolation of mutants. Wild-type bacteria from hydrolysed casein medium were suspended at $0.25 \mathrm{mg} \mathrm{dry} \mathrm{wt} \mathrm{ml-1}^{-1}$ in resuspension medium and treated with $100 \mu \mathrm{g} \mathrm{NTG} \mathrm{ml}{ }^{-1}$ at $37^{\circ} \mathrm{C}$ for $30 \mathrm{~min}$ in the dark. The cells were washed three times with resuspension medium. The washed cells were suspended in $10 \mathrm{ml}$ resuspension medium and portions $(0.1 \mathrm{ml})$ were used to inoculate 20 conical flasks (vol. $50 \mathrm{ml}$ ) each containing $5 \mathrm{ml}$ hydrolysed casein medium. The flasks were incubated at $37^{\circ} \mathrm{C}$ with shaking overnight to permit phenotypic expression of any newly induced mutations. The cultures were diluted and $0.1 \mathrm{ml}$ portions were plated on lactate-glutamate minimal agar to give about 100 colonies per plate. This agar medium was resuspension medium (Sterlini \& Mandelstam, 1969) containing $0.2 \%(\mathrm{v} / \mathrm{v})$ sodium lactate (Fisons) and $1 \%(\mathrm{w} / \mathrm{v})$ agar (Davis Gelatine, Warwick). It allows production of the brown pigment associated with sporulation in the wild-type (Iichinska, 1960; Schaeffer \& Ionesco, 1960) after 2-3 d incubation at $37^{\circ} \mathrm{C}$ while $\mathrm{Spo}^{-}$mutants produce translucent, white or light brown colonies.

Measurement of resistance to toluene, octanol, heat and lysozyme. Resistance to organic solvents, heat and lysozyme was determined as described by Jenkinson et al. (1980).

Resistance properties of free spores. To ensure that the resistance properties shown by each of the mutants was attributable to defective spores $t_{10}$ cultures of each mutant were passed through an ice-cold French pressure cell at $83 \mathrm{MPa}$, which released $>90 \%$ of the spores from their mother cells (Jenkinson et al., 1981). The resistance properties of the free spores were similar to those shown by cells not passed through the French press.

Enzyme assays. Serine protease was determined using the method described by Dancer \& Mandelstam (1975) with Remazol brilliant blue hide powder (Calbiochem) as substrate.

Alkaline phosphatase was determined by a modification (Glenn \& Mandelstam, 1971) of the method of Torriani (1960).

Glucose dehydrogenase was determined by a modification of the method of Sadoff (1966). Cultures $(50 \mathrm{ml})$ in resuspension medium were incubated at $37^{\circ} \mathrm{C}$ with shaking to stage $t_{6}$. The cultures were centrifuged $(5000 \mathrm{~g}$, $10 \mathrm{~min}$ ) and the pellets were resuspended in $2.5 \mathrm{ml} 0.5 \mathrm{M}$-sodium acetate/acetic acid solution (pH 6.5) containing $0.25 \mathrm{ml}$ glycerol $(17.5 \%, \mathrm{v} / \mathrm{v})$ and lysozyme $\left(50 \mu \mathrm{g} \mathrm{ml}^{-1}\right)$. Samples were incubated at room temperature for $10 \mathrm{~min}$ and then sonicated twice at $600 \mathrm{~W}$ ( $90 \mathrm{~s} \mathrm{each} \mathrm{time)} \mathrm{in} \mathrm{a} \mathrm{cold} \mathrm{stainless} \mathrm{steel} \mathrm{conical} \mathrm{flask} \mathrm{containing} 2.5 \mathrm{ml}$ glass beads. Sonication for $3 \mathrm{~min}$ in a Mullard sonicator released about $90 \%$ of spores from their mother cells and subsequently disrupted $>80 \%$ of the free spores. The glass beads were allowed to settle out of suspension and the supernatants were centrifuged (Beckman Microfuge, $3 \mathrm{~min}$ ) and used for assays. Assay mixtures contained $0.1 \mathrm{ml}$ 
$0.1 \mathrm{M}$-Tris $/ \mathrm{HCl}$ buffer ( $\mathrm{pH} 8.0$ ), $0.1 \mathrm{ml} 0.02 \mathrm{M}-\mathrm{NAD}, 0.1 \mathrm{ml} 1 \mathrm{mM}-\mathrm{MnSO}_{4}$ and $0.1 \mathrm{ml}$ cell supernatant. The reaction was started by the addition of $0.1 \mathrm{ml} 1 \mathrm{M}$-D-glucose and followed in a Unicam SP800 spectrophotometer at $37^{\circ} \mathrm{C}$ (wavelength $340 \mathrm{~nm}$ ). One unit of enzyme is defined as the amount catalysing the reaction of $1 \mathrm{nmol}$ substrate $\mathrm{min}^{-1}$ and specific activity is expressed as units (mg protein) ${ }^{-1}$. Soluble protein was determined using the Lowry method.

Determination of DPA. DPA was measured by the method of Janssen et al. (1958). When testing for the 'curing' effects of DPA, cultures in resuspension medium were provided with DPA (Koch-Light) at a final concentration of $100 \mu \mathrm{g} \mathrm{ml}^{-1}$ by adding appropriate volumes of a solution of DPA $\left(5 \mathrm{mg} \mathrm{ml}^{-1}, \mathrm{pH} \mathrm{7 \cdot 1}\right)$ at $t_{4}$.

Preparation of transducing lysates. PBS1 transducing lysates were prepared by the method of Coote (1972) which was based on that described by Karamata \& Gross (1970).

Transduction. Transductions with PBS1 were performed as described by Coote (1972) with the minor modification that all bacteria were washed three times in resuspension medium (not supplemented with any amino acids) before plating on appropriately supplemented lactate/glutamate agar.

Transformation. DNA was extracted by the method of Marmur (1961) and stored at $-20^{\circ} \mathrm{C}$ in $1 \mathrm{ml}$ volumes (each containing approximately $1 \mathrm{mg}$ nucleic acid). DNA preparations were not treated with ribonuclease. Competent cells were prepared by the method of Ayad \& Barker (1969). Saturating concentrations of DNA ( $>1 \mu \mathrm{g} \mathrm{ml}^{-1}$ ) were used for constructing isogenic strains and for determining recombination indices. For mapping experiments non-saturating concentrations of DNA $\left(20-100 \mathrm{ng} \mathrm{m}^{-1}\right)$ were used. In either case competent cells were incubated with the DNA at $37^{\circ} \mathrm{C}$ for $1 \mathrm{~h}$. Transformed cells and cells not treated with DNA, to serve as a recipient control, were washed three times and diluted in the minimal medium of Spizizen (1958) before plating on appropriately supplemented lactate/glutamate agar.

Preparation of isogenic strains. Saturating amounts of DNA prepared from the mutants were used to transform recipient strain MB21 Spo leu metC. Selection was for $m e t C^{+}$and generally about $5 \%$ of these transformants had also received the spo mutations of the donors by congression. The congressants had the same sporulation characteristics as their parent donor strains suggesting that the mutants did not carry multiple mutations.

Determination of RIs. Mutants $\mathrm{spo}_{1} \mathrm{met}^{+}$and $\mathrm{spo}_{2}$ met were crossed by transformation, with saturating concentrations of DNA. Recipient ( $\mathrm{metC}$ ) strains were transformed to prototrophy and the number of $\mathrm{Spo}^{+}$ transformants, obtained by congression, were scored. Wild-type DNA was used as the internal standard. The distance between the mutation was measured in terms of the RI (Lacks \& Hotchkiss, 1960). The RI is given by the ratio:

$\mathrm{Spo}^{+} / \mathrm{Met}^{+}\left(\mathrm{spo}_{1}\right.$ mutant as donor)

$\mathrm{Spo}^{+} / \mathrm{Met}^{+}$(wild-type as donor)

The RI is 1.0 when mutations are unlinked and decreases the more closely they are linked.

Extraction of spore coat proteins/SDS-PAGE. The methods described by Jenkinson et al. (1981) and Jenkinson (1981) were used.

Electron microscopy. Samples of about $10 \mathrm{ml}$ were removed from sporulating cultures and prepared for examination under the electron microscope as described by Kay \& Warren (1968).

\section{RESULTS}

\section{Isolation of mutants}

Out of about 200 sporulation-defective colonies obtained after NTG treatment, six, each of which contained a high proportion of phase grey spores, were chosen for more detailed examination. The growth rate of each mutant in liquid lactate minimal medium and liquid glucose/glutamate minimal medium was similar to that of the wild-type (data not shown) suggesting that they were specifically sporulation mutants and not damaged in their vegetative metabolism.

\section{Resistant phenotypes of mutants}

The resistance phenotype of each mutant was determined with $t_{10}$ cultures in resuspension medium. Two of the mutants, designated 517 and 518, exhibited the same phenotype, i.e. the spores were sensitive to treatment with organic solvents and heat but resistant to treatment with lysozyme (Table 2). In a third mutant, 516 , about $5-10 \%$ of the spores were lysozyme resistant while heat-resistance and organic solvent-resistance were lower by three and one orders of magnitude, respectively. Representative values for resistances are shown in Table 2 . Tolueneand octanol-resistance normally characterize stages IV and V of sporulation, respectively. 


\section{Table 2. Resistance phenotypes of strains 516,517 and 518}

The percentage of phase grey spores was determined microscopically at $t_{10}$. The resistance properties of the strains were also tested at $t_{10}$. Typically the wild-type strain produced a culture at $t_{10}$ in resuspension medium containing $80 \%$ phase bright, resistant spores, i.e. in a culture containing $5.0 \times 10^{8} \mathrm{c.f.u} . \mathrm{ml}^{-1}$, $4.0 \times 10^{8} \mathrm{ml}^{-1}$ were resistant to each of the treatments. The wild-type acquires resistance to the treatments successively in the order shown below.

\begin{tabular}{|c|c|c|c|c|}
\hline \multirow[t]{3}{*}{ 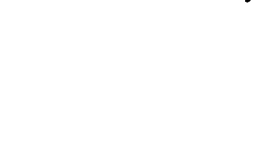 } & & \multicolumn{3}{|c|}{ C.f.u. (ml resuspension medium) $)^{-1}$} \\
\hline & & Strain 516 & Strain 517 & Strain 518 \\
\hline & Total viable count. . & $4.0 \times 10^{8}$ & $4.2 \times 10^{8}$ & $8.0 \times 10^{8}$ \\
\hline $\begin{array}{l}\text { Treatment } \\
\text { Toluene } \\
\text { Octanol } \\
\text { Heat } \\
\text { Lysozyme }\end{array}$ & & $\begin{array}{l}1.0 \times 10^{6} \\
8.0 \times 10^{6} \\
1.2 \times 10^{4} \\
3.8 \times 10^{7}\end{array}$ & $\begin{array}{l}1.7 \times 10^{5} \\
1 \cdot 1 \times 10^{5} \\
2 \cdot 4 \times 10^{5} \\
4 \cdot 2 \times 10^{8}\end{array}$ & $\begin{array}{l}1.0 \times 10^{6} \\
8.0 \times 10^{2} \\
1.0 \times 10^{2} \\
7.0 \times 10^{8}\end{array}$ \\
\hline $\begin{array}{l}\text { Percentage of phase } \\
\text { grey spores }\end{array}$ & & $90 \%$ & $80 \%$ & $80 \%$ \\
\hline
\end{tabular}

Table 3. Sporulation characteristics of strains 516,517 and 518

Values, obtained in resuspension experiments (at $t_{6}$ for serine protease, alkaline phosphatase and glucose dehydrogenase; at $t_{7}$ for DPA), are expressed as a percentage of the wild-type values. These were: serine protease 8 units $\mathrm{ml}^{-1}$ culture; alkaline phosphatase 45 units $\mathrm{ml}^{-1}$ culture; glucose dehydrogenase 48 units (mg protein) ${ }^{-1}$; and DPA $18 \mu \mathrm{g} \mathrm{ml}^{-1}$ culture. One unit of enzyme is defined as the amount catalysing the reaction of $1 \mathrm{nmol}$ substrate $\mathrm{min}^{-1}$.

\begin{tabular}{lccc} 
& \multicolumn{3}{c}{$\begin{array}{c}\text { Enzyme activity } \\
\text { (percentage of wild-type activity) }\end{array}$} \\
\cline { 2 - 5 } Strain 516 & Strain 517 & Strain 518 \\
Serine protease & 48 & 100 & 65 \\
Alkaline phosphatase & 91 & 31 & 99 \\
Glucose dehydrogenase & 40 & 75 & 60 \\
DPA & $0(<1)$ & 31 & 73
\end{tabular}

Strains 516, 517 and 518 were chosen for more detailed examination because of their resistance phenotype.

Sporulation characteristics of strains 516,517 and 518

Each of the three mutants was tested for production of serine protease, alkaline phosphatase and glucose dehydrogenase, which respectively characterize the first three stages in sporulation, and also tested for DPA which is normally associated with stage V (Waites et al., 1970). All three mutants produced serine protease, alkaline phosphatase and glucose dehydrogenase, though the amounts sometimes differed appreciably from those found in the wild-type. Two of the mutants, 517 and 518, also produced DPA but 516 was defective in DPA production (Table 3).

\section{Effect of added DPA on heat-resistance}

It is known that some types of heat-sensitive spores acquire heat-resistance if they develop in the presence of added DPA (Balassa et al., 1979). Accordingly, mutants 516, 517 and 518 were tested to determine to what extent external DPA would restore the normal phenotypic properties. The resistance phenotype of spores developed in the presence of DPA $\left(100 \mu \mathrm{g} \mathrm{ml}^{-1}\right)$ was tested at $t_{10}$. None of the mutant spores was 'cured' by the addition of DPA $\left(100 \mu \mathrm{g} \mathrm{ml}^{-1}\right)$ to the sporulating cultures at $t_{4}$.

\section{Genetic mapping of spo516, spo517 and spo518}

In preliminary transduction mapping each of the three mutants was used as donor with strain MB21 Spo ${ }^{+}$metC3 leuA8 as recipient. Separate selections were made for $\operatorname{met}^{+}$and leuA $A^{+}$ transductants on appropriately supplemented lactate-glutamate minimal media. The Spo 
Table 4. Three-factor transduction crosses with Cu448 as recipient $\left[\arg A \mathrm{Spo}^{+}\right.$ilvB (000)]

\begin{abstract}
A total of 200 transductants were tested in each cross. Sporulation phenotypes were tested by pigment production and confirmed in cases of doubt by microscopy. Cotransduction frequencies between auxotrophic markers were determined by replica plating on appropriately supplemented lactate/glutamate agar.
\end{abstract}

\begin{tabular}{|c|c|c|c|c|c|c|c|c|c|}
\hline \multicolumn{3}{|c|}{ Donor: $\mathrm{arg}^{+} \mathrm{Spo}^{-} i \mathrm{lv}^{+}(111)$} & \multirow{2}{*}{\multicolumn{4}{|c|}{$\begin{array}{l}\text { No. of transductants } \\
\text { in the different classes } \\
\text { of recombinants }\end{array}$}} & \multirow[b]{3}{*}{ Possible order } & \multirow{3}{*}{$\begin{array}{l}\text { No. of transductants } \\
\text { in the cross requiring } \\
\text { multiple cross-overs }\end{array}$} & \multirow{3}{*}{$\begin{array}{c}\text { Suggested } \\
\text { order }\end{array}$} \\
\hline \multirow{2}{*}{$\begin{array}{c}\text { Selected } \\
\text { marker }\end{array}$} & \multicolumn{2}{|c|}{$\begin{array}{l}\text { Unselected } \\
\text { marker }\end{array}$} & & & & & & & \\
\hline & $-1-$ & --1 & 100 & 101 & 110 & 111 & & & \\
\hline $\arg ^{+}$ & spo516 & $i l v^{+}$ & 62 & 12 & 97 & 29 & $\left\{\begin{array}{l}\text { arg spo ilv } \\
\text { arg ilv spo } \\
\text { spo arg ilv }\end{array}\right.$ & $\begin{array}{r}12 \\
97 \\
*\end{array}$ & arg spo ilv \\
\hline $\arg ^{+}$ & spo517 & $i l v^{+}$ & 70 & 9 & 78 & 43 & $\left\{\begin{array}{l}\text { arg spo ilv } \\
\text { arg ilv spo } \\
\text { spo arg ilv }\end{array}\right.$ & $\begin{array}{r}9 \\
78 \\
*\end{array}$ & arg spo ilv \\
\hline $\arg ^{+}$ & spo518 & $i l v^{+}$ & 69 & 10 & 91 & 30 & $\left\{\begin{array}{l}\text { arg spo ilv } \\
\text { arg ilv spo } \\
\text { spo arg ilv }\end{array}\right.$ & $\begin{array}{r}10 \\
91 \\
*\end{array}$ & arg spo ilv \\
\hline
\end{tabular}

phenotype of the transductants was determined by pigment production and confirmed in cases of doubt by microscopy. The three mutations were not linked to metC but were all about $80 \%$ linked to leuA, the values being: spo516, 83\% (661/792 transductants); spo517, 79\% (575/731 transductants) and spo518, 83\% (820/987 transductants). The approximate map positions of spo516, spo517 and spo518 were confirmed with a different recipient strain, Cu448 phe $i l v B \arg A \operatorname{trp} C 2$, selection being made for $i l v B^{+}$transductants (ilv $B$ is adjacent to $l e u A$ at the $250^{\circ}$ position on the circular $B$. subtilis linkage map (Henner \& Hoch, 1980). In this series of experiments linkages to $i l v B$ were as follows: spo516, 88\% (734/831 transductants); spo517, $81 \%$ (1700/2091 transductants) and spo518,88\% (1372/1560 transductants).

In transformation experiments with $\mathrm{Cu} 448$ as recipient and non-saturating amounts of DNA (20 $\left.\mathrm{ng} \mathrm{ml}^{-1}\right)$ linkages to ilvB were: spo516, 51\% (1228/2385 transformants); spo517, 59\% (1476/2519 transformants) and spo518, 52\% (525/1003 transformants).

Although the three mutations were cotransformable with $i l v B$, other auxotrophic markers in the region were too distant to enable more detailed mapping experiments to be made by transformation. It was therefore necessary to use PBS1-mediated transduction to order the mutations with respect to other markers in the $i l v B$ region. In three-factor crosses with each of the mutants as donor and $\mathrm{Cu} 448$ as recipient, $\arg A^{+}$transductants were selected and scored for cotransduction of the unselected markers spo and $i l v B$. The results (Table 4) show that spo516, spo517 and spo5 18 are clustered together between the outside markers $i l v B$ and $\arg A$. These markers lie between the $250^{\circ}$ and $260^{\circ}$ positions on the circular linkage map of $B$. subtilis (Henner \& Hoch, 1980).

The relative order of spo516, spo517 and spo5 18 was determined by reciprocal transformation crosses with non-saturating concentrations of DNA $\left(100 \mathrm{ng} \mathrm{m}^{-1}\right)$. The recipients, 516.448 , 517.448 and 518.448, were derived as shown in Table 1. ilv $B^{+}$transformants were selected and scored for their sporulation phenotypes. The order can be deduced from a consideration of the number of cross-overs needed to give $\mathrm{Spo}^{+}$recombinants.
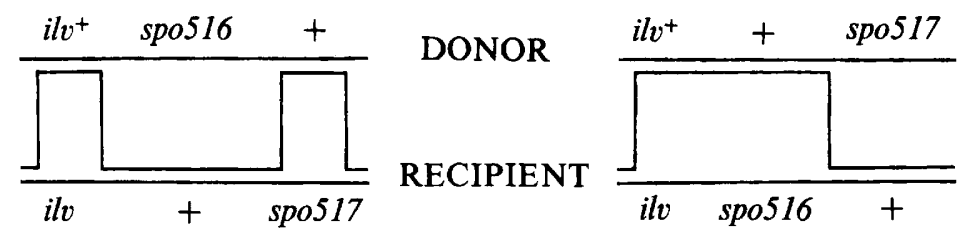
Table 5. Relative order of spo516, spo517 and spo518 mutations examined by transformation crosses

Non-saturating concentrations of DNA $\left(100 \mathrm{ng} \mathrm{ml}^{-1}\right)$ were used for each transformation cross. Sporulation phenotypes were tested by pigment production and confirmed in cases of doubt by microscopy. The data suggest that the gene order is ilvB spo516 spo518 spo517 (for explanation see text).

Donor strain Recipient strain

516 (spo516 trpC2) 517 (spo517 trpC2) 516 (spo516 trpC2) $518(\operatorname{spo5} 18 \operatorname{trp} C 2)$ 517 (spo517 trpC2) 518 (spo518 trpC2)
517.448 (ilvB spo517 phe $\operatorname{trpC2} \arg A^{+}$)

516.448 (ilvB spo516 phe trpC2 $\arg A^{+}$)

518.448 (ilvB spos18 phe trpC2 $\arg A^{+}$)

516.448 (ilvB spo516 phe trpC2 $\arg A^{+}$)

518.448 (ilvB spos18 phe trpC2 $\arg A^{+}$)

517.448 (ilvB spo517 phe trpC2 $\arg A^{+}$)
No. of ilvB $B^{+}$

No. of transformants which ilv $B^{+}$transformants were $\mathrm{Spo}^{+}$

3120

2454

4077

2740

1726

4300
$70(2 \cdot 2 \%)$

$410(16.7 \%)$

$78(1.9 \%)$

$370(13.5 \%)$

$208(12 \cdot 1 \%)$

$83(1.9 \%)$

\section{Table 6. RI values for mutants 516,517 and 518}

Saturating concentrations of DNA $\left(>1 \mu \mathrm{g} \mathrm{ml}^{-1}\right)$ were used for each cross. Sporulation phenotypes were tested by pigment production on lactate/glutamate agar and confirmed in cases of doubt by microscopy.

Donor strain

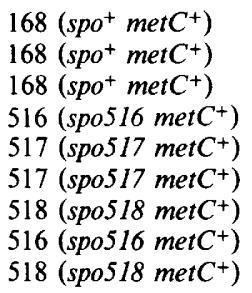

Recipient strain

$516.21($ spos 16 metC)

$517.21($ spo5 17 metC)

518.21 (spo518 metC)

517.21 (spo517 metC)

516.21 (spo516 metC)

518.21 (spo518 metC)

517.21 (spo517 metC)

518.21 (spo518 metC)

516.21 (spo516 metC)
No. of met $C^{+}$transformants (selected marker)

5916
8388
5665
4356
6259
4207
5228
4828
4352

8388

5665

4356

6259

4207

4828

4352
No. of $\mathrm{metC}^{+}$ transformants which were $\mathrm{Spo}^{+}$ RI

$\begin{array}{rc}460(7.9 \%) & - \\ 763(9.1 \%) & - \\ 425(7.5 \%) & - \\ 292(6.7 \%) & 0.74 \\ 358(5.7 \%) & 0.72 \\ 302(7.2 \%) & 0.96 \\ 347(6.6 \%) & 0.73 \\ 100(2.1 \%) & 0.28 \\ 95(2.2 \%) & 0.28\end{array}$

It can be seen that in the first cross, four cross-over events are required to yield the $\mathrm{Spo}^{+}$ phenotype, whereas in the reciprocal cross only two are required. The results (Table 5) showed that with spo516 (donor) $\times$ spo517 (recipient), $\mathrm{Spo}^{+}$transformants were rare $(2.2 \%)$ whereas in the reciprocal cross the value was $16.7 \%$. This indicates that spo516 is the nearer of the two mutations to $i l v B$. Examination of the remaining data (Table 5) in this way suggests that the relative order is $i l v B$ spo5 16 spo518 spo517.

\section{RIs between spo516, spo517 and spo518}

To obtain a measure of the map distances between the mutations, RIs between each pair of mutants were determined. The RIs between strains 516 and 517, 516 and 518 and 517 and 518 are shown in Table 6. The RI data suggest that spo516, spo517 and spo518 lie in three separate genes but that spo516 and spo518 may be in the same sporulation locus; spo517 is clearly in a different sporulation locus virtually unlinked to the other two.

\section{Gel electrophoresis of spore coat proteins produced by strains 516, 517 and 518}

Spores from strains 516, 517, 518 and 168 (wild-type) were prepared from $t_{9}$ resuspended cultures. The coat proteins were fractionated by SDS-PAGE (Fig. 1). The four major coat proteins identified by Jenkinson $e$ al . (1981) have been indicated in Fig. 1. It can be seen that each mutant has the major proteins of the wild-type $(36 \mathrm{~K}, 20 \mathrm{~K}, 12 \mathrm{~K}$ and $11 \mathrm{~K}$, where $\mathrm{K}=$ $\mathrm{kDal}$ ). Although minor quantitative differences occurred in each of the mutants they are unlikely to be significant (Jenkinson et al., 1981). 


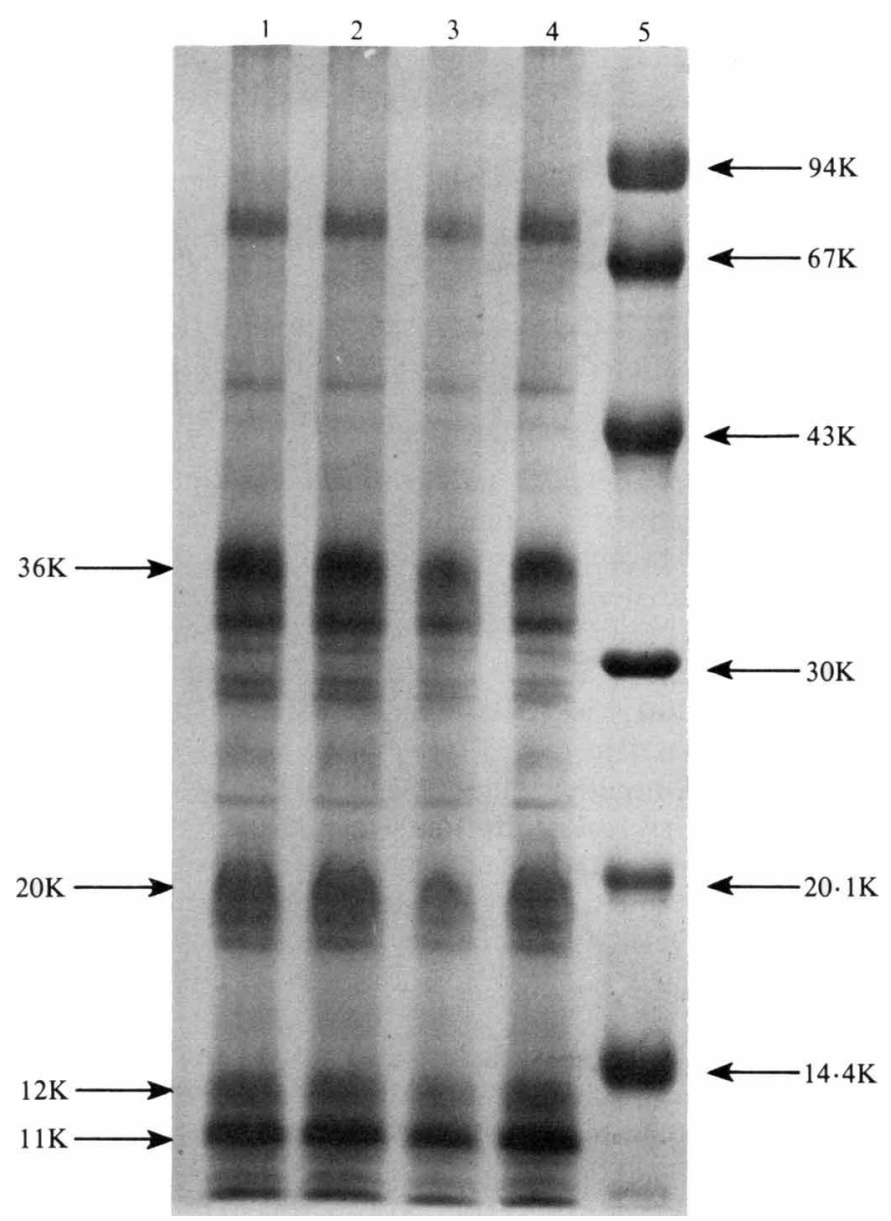

Fig. 1. SDS-PAGE patterns (stained with Coomassie blue) of proteins extracted from coats of spores of strains 516, 517, 518 and 168 (wild-type). Lane 1, 168; lane 2, 516; lane 3,517; lane 4, 518; lane 5, standards. $\mathrm{K}=\mathrm{kDal}$.

\section{Electron microscopy of strains 516, 517 and 518}

Electron micrographs were prepared from spores of $t_{7}$ cultures of strains $516,517,518$ and 168 (wild-type). No consistent structural differences could be seen between any of the strains and the micrographs are therefore not shown.

\section{DISCUSSION}

The mutants described in this paper were chosen for study because they possessed a previously undescribed phenotype, i.e. they were lysozyme-resistant but relatively sensitive to organic solvents and to heat. Under standard conditions of sporulation, two of the mutants, 517 and 518 , gave normal numbers of lysozyme-resistant spores $\left(>10^{8} \mathrm{ml}^{-1}\right)$; the third, mutant 516 , produced only $5-10 \%$ of this number. Each mutant grew as well as the wild-type under a variety of conditions, suggesting that they were blocked in functions specifically concerned with sporulation and not damaged in their vegetative metabolism. Each mutant produced a large number of phase grey spores and their properties suggest that they were blocked at stage $\mathrm{V}$. Like many mutants blocked at stage $\mathrm{V}$ all three are oligosporogenous rather than asporogenous and also form a significant number of phase bright spores. 
The fact that the mutants are oligosporogenous and that the sporulation properties of each mutant could be transferred to $\mathrm{Spo}^{+}$backgrounds by single transduction and transformation events makes it highly unlikely that any of them is damaged in more than one sporulation gene. This assumption was substantiated by the fact that the three mutants reverted spontaneously to wild-type at a frequency of about $10^{-8}$ (data not shown) showing that the lesions are point mutations. Furthermore, the transformants and transductants derived from each of the mutants had the same sporulation phenotype as their parents. The transduction and transformation data favour the view that spo516, spo517 and spo518 identify three separate genes comprising two new sporulation loci since transformation data suggest that spo516 and spo518 are likely to be in the same locus (RI 0.28; see Piggot \& Coote, 1976) whereas spo517 seems more likely to have occurred in a separate sporulation locus from both spo516 and spo518 (RIs >0.7). The new loci map in the phe-arg $A$ region of the $B$. subtilis chromosome. Since a mutant described by Rosenbluh et al. (1981) has already been designated spoVG, the designation spoVH will be used for mutants 516 and 518. To avoid typographical confusion with stage VI mutants the designation spoVI will not be used and 517 will be designated spoVJ.

The biochemical properties of the mutants with respect to production of enzymes associated with earlier stages of sporulation (Waites et al., 1970) was as expected; the three mutants all produced serine protease, alkaline phosphatase and glucose dehydrogenase. However, one of the three mutants, 516, was also defective in DPA production (DPA production is a stage $\mathrm{V}$ event). Unlike some other DPA-negative mutants, e.g. spoVF (Piggot \& Coote, 1976) and dpa-1 (Balassa et al., 1979), 516 was not restored to full heat-resistance ('cured') by the provision of exogenous DPA. It may be that the DPA-negative and heat-sensitive phenotype is due to the pleiotropic nature of the spo516 mutation, e.g. the genes for the heat and DPA characters may share a common mechanism of regulation which has been altered by spo516. Strains 517 and 518 are DPA-positive and, as expected, the provision of exogenous DPA did not render them heatresistant.

It now appears that the majority of events associated with the later stages of sporulation, including the development of physical resistance properties and the germination properties of the spores, involve incorporation into the spore coat of proteins synthesized during the earlier stages of the sporulation process (Dion \& Mandelstam, 1980; Jenkinson et al., 1981). Although 516,517 and 518 gave similar SDS-PAGE patterns of spore coat proteins compared to the wildtype it is possible that their unusual resistance properties may be due to faulty assembly of spore coat proteins or perhaps to a failure to synthesize one or more minor coat polypeptides not normally detected by SDS-PAGE.

The failure of electron microscopy to reveal any differences between the mutant and wild-type spores is not surprising because only a gross defect in the coat or cortex would be expected to produce a recognizable change in morphology.

This work was supported by the Science Research Council. I should like to thank Dr Howard Jenkinson for his assista1 ce with SDS-PAGE experiments; Dr Michael Yudkin for helpful criticism and Miss Mary Bergin for assistance with electron microscopy. My special thanks go to Professor Joel Mandelstam for his untiring interest and invaluable advice.

\section{REFERENCES}

AYAD, S. R. \& BARKER, G. R. (1969). The integration of donor and recipient deoxyribonucleic acid during transformation of Bacillus subtilis. Biochemical Journal 113, 167-174.

Balassa, G., Milhaud, P., Raulet, E., Silva, M. T.\& Sousa, J. C. F. (1979). A Bacillus subtilis mutant requiring dipicolinic acid for the development of heat-resistant spores. Journal of General Microbiology 110, 365-379.

CoOTE, J. G. (1972). Sporulation in Bacillus subtilis. Genetic analysis of oligosporogenous mutants. Journal of General Microbiology 71, 17-27.
Dancer, B. N. \& Mandelstam, J. (1975). Production and possible function of serine protease during sporulation of Bacillus subtilis. Journal of Bacteriology 121, 406-410.

Dion, P. \& Mandelstam, J. (1980). Germination properties as marker events characterizing later stages of Bacillus subtilis spore formation. Journal of Bacteriology 141, 786-792.

GlenN, A. R. \& Mandelstam, J. (1971). Sporulation in Bacillus subtilis 168. Comparison of alkaline phosphatase from sporulating and vegetative cells. Biochemical Journal 123, 129-138. 
Henner, D. J. \& Hoch, J. A. (1980). The Bacillus subtilis chromosome. Microbiological Reviews 44, 5782.

IICHINSKA, E. (1960). Some physiological features of asporogenous mutants of bacilli. Microbiology (U.S.S.R.) 29, 147-150. [English translation.]

JANSSEN, F. W., LUND, A. J. \& ANDERSON, L. E. (1958). Colorimetric assay for dipicolinic acid in bacterial spores. Science 127, 26-27.

JENKINSON, H. F. (1981). Germination and resistance defects in spores of a Bacillus subtilis mutant lacking a coat polypeptide. Journal of General Microbiology 127, 81-91.

Jenkinson, H. F., Kay, D. \& Mandelstam, J. (1980). Temporal dissociation of late events in Bacillus subtilis sporulation from expression of genes that determine them. Journal of Bacteriology 141, 793805.

Jenkinson, H. F., SAWyer, W. D. \& Mandelstam, J. (1981). Synthesis and order of assembly of spore coat proteins in Bacillus subtilis. Journal of General Microbiology 123, 1-16.

Karamata, D. \& Gross, J. D. (1970). Isolation and genetic analysis of temperature-sensitive mutants of B. subtilis defective in DNA synthesis. Molecular and General Genetics 108, 277-287.

KAY, D. \& WARREN, S. C. (1968). Sporulation in Bacillus subtilis. Morphological changes. Biochemical Journal 109, 819-824.

LACKS, S. \& Hotchisiss, R. D. (1960). A study of the genetic material determining an enzyme activity in Pneumococcus. Biochimica et biophysica acta 39, 508518.

MARMUR, J. (1961). A procedure for the isolation of deoxyribonucleic acid from microorganisms. Journal of Molecular Biology 3, 208-218.

MANDELSTAM, J. (1969). Regulation of bacterial spore formation. Symposia of the Society for General Microbiology 19, 377-402.

MANDELSTAM, J. (1976). Bacterial sporulation: a problem in the biochemistry and genetics of a primitive developmental system. Proceedings of the Royal Society B193, 89-106.

Piggot, P. J. \& CoOTE, J. G. (1976). Genetic aspects of bacterial endospore formation. Bacteriological $R e$ views 40, 908-962.

Rosenblut, A., BonNer, C. D. B., Losick, R. \& FITZJAMES, P. C. (1981). Identification of a new developmental locus in Bacillus subtilis by construction of a deletion mutation in a cloned gene under sporulation control. Journal of Bacteriology 148, 341351.

RYTER, A. (1965). Étude morphologique de la sporulation de Bacillus subtilis. Annales de l'Institut Pasteur 108, $40-60$.

SADOFF, H. L. (1966). Glucose dehydrogenase soluble. I. Bacillus cereus. Methods in Enzymology 9 , 103-107.

SCHAEFFER, P. \& IONESCO, H. (1960). Contribution à l'étude génétique de la sporogenèse bacterienne. Comptes rendus hebdomadaires des séances de l'Académie des sciences 251, 3125-3127.

SPIZIZEN, J. (1958). Transformation of biochemically deficient strains of Bacillus subtilis by deoxyribonucleate. Proceedings of the National Academy of Sciences of the United States of America 44,10721078.

Sterlini, J. M. \& MandelstaM, J. (1969). Commitment to sporulation in Bacillus subtilis and its relationship to development of actinomycin resistance. Biochemical Journal 113, 29-37.

TORRIANI, A. (1960). Influence of inorganic phosphate in the formation of phosphatases by Escherichia coli. Biochimica et biophysica acta 38, 460-479.

WaITES, W. M., KAY, D., DAWES, I. W., WOOD, D. A., WARREN, S. C. \& MANDElstam, J. (1970). Sporulation in Bacillus subtilis. Correlation of biochemical events with morphological changes in asporogenous mutants. Biochemical Journal 118, 667-676. 